4 Contact Information:

5 1. Swati Saxena: Research Scholar, Ladybird Research Laboratory, Department of

9 2. Geetanjali Mishra: Associate Professor, Ladybird Research Laboratory, Department

\section{Mating system modulates mate selection in aphidophagous ladybird, Menochilus sexmaculatus} Zoology, University of Lucknow, Lucknow- 226007, India; email: swati90lko@gmail.com of Zoology, University of Lucknow, Lucknow- 226007, India; email: geetanjalimishra@hotmail.com

3. Omkar*: Professor, Ladybird Research Laboratory, Department of Zoology, University of Lucknow, Lucknow- 226007, India, email:omkaar55@ hotmail.com

*Corresponding author email: omkar.lkouniv@ gmail.com

Short running title: Mating systems in ladybirds

\section{ABSTRACT}

Mate competition and selection of mates is strongly influenced by the organism's mating system. Monogamous matings provide more benefits as compared to polygamous matings. However, it has been proven that in polygamous systems, females gain benefits from the males, therefore indulging in multiple mating, leading males to access maximum females. In zigzag ladybird, Menochilus sexmaculatus, mate choice has been studied on several pre-and postcopulatory factors. However, mate choice as a function of mating system is still remains 
untouched. In the present study, we hypothesised that the mating system modulates mate selection of beetles. Adults were held in different mating systems and then males and females were tested in mate choice trials. Polygynous males were more preferred over monogynous males. However, males preferred monandrous females over polyandrous females. In a second experiment, we also included relatedness as additional factor. In female mate choice trials, females preferred unrelated monogynous males which were earlier rejected over related polygynous and in male mate choice trials, males preferred unrelated polyandrous females over related monandrous females. The results were not confined only to mate choice but significant effect was also observed on time to commence mating, copulation duration, fecundity and percent egg viability.

KEYWORDS: Fecundity, Monogamous, Polygamous, Relatedness

\section{INTRODUCTION}

Mating systems describe how pairing of male and female occurs while choosing a mate. It basically consists of two types of mating systems i.e. monogamy and polygamy. Monogamy involves the mating with a single mate (repetitive matings). In case of females, it can be monandry and in case of males it is called mongyny. If both the sexes mate with multiple mates they are considered polygamous (Emlen \& Oring, 1977; Thornhill \& Alcock, 1983; Davies, 1991; Shuster \& Wade, 2003). While monogamy is much prized in the human social context, true genetic monogamy is extremely rare in the animal world, and even in presumably monogamous systems, single matings in a lifetime are rarest of the rare cases. In spite of several costs of multiple matings, such as reduced foraging, reduced longevity or even risks of physical injury such as damage of the female's reproductive tract (Thornhill \& Alcock, 1983; Arnqvist, 1989; Yasui, 1998; Arnqvist \& Nilsson, 2000; Rolff \& Siva-Jothy, 2002; Simmons, 2005), multiple matings are common to gain reproductive fitness. For female mating with different males is termed as polyandry and for males mating with 
52 different females called as polygyny. Some researchers have proposed that mating system

53 reflects how much parental care each sex provides (Vehrencamp \& Bradbury, 1984;

54 Reynolds, 1996; Shuster \& Wade, 2003). There are several theories, such as Bateman's

55 principles (Bateman, 1948), parental investment (Trivers, 1972), etc. that demonstrate that

56 males produce numerous, small gametes (sperm) while females produce large and limited

57 number of gametes (eggs). Experiments on Drosophila by Bateman revealed that males gain reproductive success by multiple matings. However, these predictions were not in accordance with the empirical data. Several researchers have suggested that females also mate with different males to gain benefits (Tang-Martinez, 2010; Gowaty et al.,2012). A number of hypotheses have been proposed to explain why polyandry or multiple matings exists in spite of it being costly. In many species, such as in Drosophila subobscura Collin, females are monogamous but upon receipt of certain nuptial gifts they mate multiply (Smith, 1956; Holman et al., 2008). In jewel wasps, Nasonia vitripennis, wild females are generally monogamous and laboratory females are reluctant to remate (Burton-Chellew et al., 2007). However, after females were reared for longer periods under laboratory conditions, they tend to mate multiply. Studies in N. vitripennis also revealed that tendency to mate multiple times has been found to be heritable (Shuker et al., 2007). seaweed fly, Coelopa frigida Fabricius, (Blyth \& Gilburn, 2006), females resist matings with mounted males by shaking, kicking, curving which are energetically costly responses. In water striders, mating is costly to females by increasing their probability of predation or decreasing their longevity due to physical damage (Arnqvist, 1989). Besides physical injury, chemical damage has also been reported in D. melanogaster. Male ejaculate may contain some toxic substances that can cause side effects on the female life span (Gems \& Riddle, 
remating rate and sexual receptivity (Eberhard, 1996). In certain instances, it was found that multiple matings hamper the reproductive success (Ronn et al., 2006; Bezzerides et al., 2008; Pai \& Beenasconi, 2008). In the cabbage beetle, Colaphellus bowringi Baly, monogamy was more advantageous for female than polyandry (Liu et al., 2010). However, contrary to this monogamy increase the chances of homozygosity. This was found to affect the social interactions of offspring, with those born to monogamous pairs having less prominent interactions than those born to the heterozygous offspring of polygamous pairs (Evans \& Kelly, 2008). Besides all these costs, there are several benefits of multiple matings. They can be categorised into non-genetic or direct benefits and genetic or indirect benefits. Several empirical studies have addressed the effects of multiple mating on female fitness in various ways (Ridley, 1988; Vahed, 1998) focusing on the act of mating per se, the presence of sperm or the transfer of accessory substances. A large number of accessory substances are transferred to females that enhance the female reproductive performance (Gromko et al., 1984) and also affect the egg production (Opp \& Prokopy, 1986) and laying. Indirect benefits include offspring attractiveness ('sexy-sons' hypotheses), their viability (Tregenza \& Wedell, 2002; Gowaty et al.,2010; Omkar et al.,2010; Firman and Simmons, 2012), genetic heterogeneity, and phenotypic diversity (Barbosa \& Magurran, 2010; Foerster et al., 2003).

Ladybirds are considered highly promiscuous; they can copulate for long time and change their mating partners frequently (Nedved \& Honek, 2012). Polymorphism in ladybirds also tends to be one of the reasons behind multiple matings (Slogget \& Honek et al.,2012) as it is one of the genetic marker and it is often maintained as a result of sexual selection (Muggleton et al.,1975; O’Donald \& Majerus,1984). Omkar et al. (2010) reported that 11 matings were required to maximize the fecundity in Coelophora saucia (Mulsant). Studies on Coccinella transversalis $\mathrm{F}$. and $C$. septempunctata reported that male virility diminishes with increase in number of matings, thus reducing female's fecundity (Michaud et 
102

103

104

105

al., 2013). In Menochilus sexmaculatus (Fabricius) a positive effect of multiple mating on fecundity was recorded (Dubey, 2016).

Thus, in contention of the above information, it was hypothesised that polygamous individuals will be more preferred over monogamous in $M$. sexmaculatus. The present study was conducted to observe the mate choice between individuals of different mating system by monogamous and polygamous males or females. As it was earlier studied that these beetles show rejection towards related individuals (Saxena et al., 2016), to extend our study the choice was also given between related and unrelated individuals and individuals of different mating systems to study whether mating system can alter the rejection behaviour of these beetles towards related partners.

\section{MATERIALS AND METHODS}

\section{Experimental species}

Menochilus sexmaculatus, commonly known as zigzag beetle, was selected for experimentation due to its abundance in local fields, high reproductive output, and wide prey range (Agarwala \& Yasuda 2000). Presence of basic information about pre-(Dubey et al., 2016a, b) and post-copulatory mate choice behaviour (Chaudhary et al., 2015) further provides a good foundation to build upon.

\section{Collection and rearing of experimental species}

Adults of $M$. sexmaculatus (50 beetles) were collected from the agricultural fields of Lucknow, India $\left(26^{\circ} 50^{\prime} \mathrm{N}, 80^{\circ} 54^{\prime} \mathrm{E}\right)$. Adult males and females were paired in plastic Petri dishes (hereafter, $9.0 \times 2.0 \mathrm{~cm}$ ) and were fed on ad libitum supply of cowpea aphid, Aphis craccivora Koch (Hemiptera: Aphididae) raised on cowpea, Vigna unguiculata L. reared in a glasshouse (at $25 \pm 2^{\circ} \mathrm{C}, 65 \pm 5 \%$ R.H.). The Petri dishes containing mating pairs were placed in Biochemical Oxygen Demand (BOD) incubators (Yorco Super Deluxe, YSI-440, New Delhi, India) at $27 \pm 1^{\circ} \mathrm{C} ; 65 \pm 5 \% \quad$ R.H.; $14 \mathrm{~L}: 10 \mathrm{D}$ and inspected twice daily (1000 and $1500 \mathrm{~h}$ ) for 
oviposition. The eggs laid were separated daily and held in plastic Petri dishes (size as above) until hatching. Each hatched larva was reared individually in Petri dishes (size as above) until adult emergence.

\section{Rearing of adults of different mating system}

Monogamous adults were prepared from the stock culture. For monandrous females, 5-day old unmated females were allowed to mate with 5-day-old unmated males. After their natural dislodging, both male and female were kept separately in new Petri dishes (size as above) and provided ad libitum supply of aphids over a period of 5 days. Thereafter, the same pair was reformed and allowed to mate at 24 hours interval, leading to the total of five matings.

For polyandrous females, 5-day old unmated female was allowed to mate with 5-day old unmated unrelated male until the completion of the mating. After postmating, beetles were separated. After 24 hours same females were provided with new once-mated male. Mating with different males continued for the next 5-days (mating status of the new males were kept same as that of female). Thus, monogynous 5-day-old males were allowed to mate with same unmated 5-day-old unrelated females at the interval of 24 hours for the next 5 days, whereas polygynous condition, 5-day old unmated males were allowed to mate with different females of the same mating status at every 24 hours for the next five days.

\section{Effect of mating system and relatedness on mate choice}

\section{(a) Mating system effects}

In female mate choice trials, 10-day old monogynous and polygynous males were introduced simultaneously in the new Petri dish (size as above). A focal 10-day-old monandrous female was placed into this arena within 5 minutes of introducing the males. This setup allowed full interaction of the focal monandrous female with both the males present in the arena. If mating 
occurred, the unselected male was removed and mating was allowed to complete. If no choice was made within 30 minutes, the trial was discarded. To distinguish between different males, the adults were colour marked with a yellow or green dot on the posterior edge of elytra. To avoid the biasness due to colour marks, it was randomized in all the replicates of the mate choice trials. Similar mate choice trials were conducted for polyandrous females. All adults were unrelated in these treatments.

In male mate choice trials, one 10-day-old monogynous male was introduced in the new Petri dish (size as above). 10-day old unrelated monandrous and polyandrous females were introduced simultaneously. If no choice was made within 30 minutes, the replicate was discarded. Marking of both the females was done in similar way as above. Similar mate choice trials were conducted for polygamous males. All the mate choice trials were conducted in 15 replicates.

\section{(b) Relatedness and mating system effects}

To additionally study the effect of relatedness and the mating system, newly emerged females $(0-2 \mathrm{~h}$ old $)$ were taken from the stock of related individuals, which was created and maintained as per Saxena et al. (2016), where the offspring of the random pairings from a laboratory stock populations were mated with their siblings creating a related stock. A 5-day old related female (female from the related stock) was allowed to mate with one related males for the next five days at 24 hours interval. Such females were called as related monogamous females. For related polyandrous females, they were allowed to mate with different related males for next five days at 24 hours interval. Status of the male was kept according to that of females.

Similarly, a 5-day-old male taken from the above related stock was allowed to mate with single related female for the next five days at 24hours intervals (related monogynous males). 
174 Another 5-day old related male was allowed to mate to with different related females at 175 24hours interval for the next five days (related polygynous male).

176 Subsequently female mate choice trials were set up as above. 10-day old related monandrous 177 females were given the choice between related polygynous male and unrelated monogynous 178 male. Similar choice was given to related polyandrous females. In corresponding male mate 179 choice trials, both 10-day old related monogynous and polygynous males were given the 180 choice of related monandrous and unrelated polyandrous females. Marking of the adults was 181 done as above. All the trials were conducted in 15 replicates.

\section{Effect of mating system and relatedness on mating and reproductive parameters}

183 The effect of male and female mating system was observed on following combinations: (1)

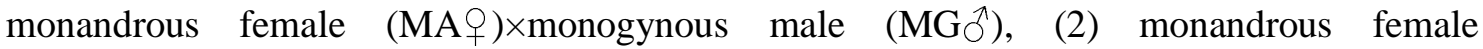
(MAㅇ)×polygynous male $\left(\mathrm{PG}_{O}^{\wedge}\right),(3)$ monandrous female (MAㅇ) $\times$ related polygynous male $\left(\mathrm{RPG}_{0}^{\wedge}\right),(4)$ polyandrous female (PAㅇ)×monogynous male $\left(\mathrm{MG}_{\bigcirc}^{\Uparrow}\right),(5)$ polyandrous female

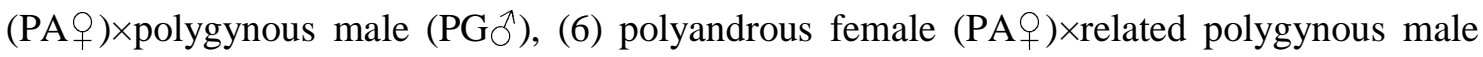
$\left(\mathrm{RPG}_{0} \hat{)}\right),(7)$ monogynous male $\left(\mathrm{MG}_{0} \hat{)}\right) \times$ polyandrous female (PAㅇ),(8) monogynous male $\left(\mathrm{MG}_{0} \hat{)} \times\right.$ related polyandrous female $\left(\mathrm{RPA}+\right.$ ), $(8)$ polygynous male($\left(\mathrm{PG}^{\hat{}}\right) \times$ monandrous female (MA + ), and (9) polygynous male( $\left.\mathrm{PG}_{\bigcirc}\right) \times$ related monandrous female (RMA treatment consisted of 15 replicates. These mating treatments include the pairs obtained from the above mate choice trials. The mating parameters, i.e. time of commencement of mating (from the introduction in Petri dish to the establishment of genital contact) and copulation duration

194 (from genital contact till the natural disengagement) of the above pairs were recorded. Daily oviposition and percent viability were recorded for the next 7 days in all treatments. 
197 Data on mate choice was subjected to chi-square $\left(\chi^{2}\right)$ goodness-of-fit analysis. Data on mating

198

199

200 parameters and reproductive parameters were first tested for normality (KolmogorovSmirnoff) and homogeneous (Bartlett's) distribution. On being found normally distributed with homogeneous variation, the data were subjected to two-way analysis of variance (ANOVA) with mating system of male and female as individual independent factors. The analysis was followed by the comparison of means using post hoc Tukey's honest significance test at 5\%. All statistical analyses were conducted using $\mathrm{R}$ studio Version 1.2.1335 statistical software.

\section{RESULTS}

\section{Effect of mating system and relatedness on mate choice}

Results on mate choice revealed that when monandrous females were given the choice between monogynous and polygynous males then latter were preferred (Fig.1a). Same results were observed when polyandrous females were given the same choice (Fig. 1b). However, when both females were given the choice of related polygynous males and unrelated monogynous males then unrelated monogynous males were preferred as mates (Fig. $1 \mathrm{a}$ and b).

In monogynous male mate choice trials, monandrous females were preferred over the polyandrous females (Fig. 2a). Similar choice was made by polygynous males (Fig. 2b). When related monandrous and unrelated polyandrous females were kept in mate choice trials then both males preferred unrelated polyandrous females over the related monandrous females (Fig. 2a and b).

\section{Effect of mating system and relatedness on mating and reproductive parameters}

Time of commencement of mating (TCM) was significantly influenced by the mating system of males $\left(F_{2,84}=272.98 ; P=0.000\right)$ but not by mating system of females $\left(F_{2,84}=0.95 ; P=0.332\right)$. 
221 The interaction between mating system of males and females was also significant $\left(F_{2}\right.$,

$22284=4.43 ; P=0.014)$. Time of commencement of mating was longer when monandrous and

223 polyandrous females mated with unrelated monogynous males, followed by related

224 polygynous males, and shortest when mated with unrelated polygynous males (Fig.3a).

When monogynous and polygynous males were mated with females of varying

mating system, Time of commencement of mating was not significantly affected by mating

system of males $\left(F_{2,84}=0.02 ; P=0.891\right)$ but was significantly influenced by mating system of

females $\left(F_{2,89}=405.72 ; P=0.000\right)$ The interaction between mating system of males and

females was also significant $\left(F_{2,84}=3.93 ; P=0.023\right)$. TCM was high when monogynous and

polygynous males mated with unrelated polyandrous females and related monandrous

females while low when both were mated with unrelated monandrous females (Fig 3b).

Results of two-way ANOVA revealed the significant effect of male mating system

$\left(F_{2,84}=20.36 ; \quad P=0.000\right)$ and insignificant effect of female mating system $\left(F_{2,84}=2,39\right.$;

$P=0.126)$ on copulation duration when monandrous and polyandrous females mated with

males of varying mating system. The interaction between males and females mating system

was also insignificant $\left(F_{2,84}=0.06 ; P=0.937\right)$. Copulation duration was highest when

monandrous and polyandrous females were mated with unrelated polygynous males and

lowest when mated with unrelated monogynous males and related polygynous males (Fig 4a).

When males mated with females of different mating systems, copulation duration was significantly influenced by mating system of females $\left(F_{2,89}=110.15 ; P=0.000\right)$ but not by the mating system of males $\left(F_{1,89}=0.00 ; P=1.000\right)$. The interaction between male and female mating systems was also insignificant $\left(F_{2,}{ }_{89}=0.43 ; P=0.655\right)$. Copulation duration was 
unrelated polygynous males than when mated with unrelated monogynous males and related polygynous males (Fig. 5a).

When monogynous and polygynous males were mated with females of varying mating system, fecundity was significantly influenced by the mating system of females $\left(F_{2,89}=3587.51 ; P=0.000\right)$ and had no significant effect of the mating system of males $\left(F_{1,89}=0.00 ; P=0.975\right)$ The interaction between males and females mating system was also insignificant $\left(F_{2,89}=0.07 ; P=0.933\right)$. Maximum number of eggs were laid when monogynous and polygynous males mated with unrelated monandrous females (Fig. 5b) and minimum when mated with unrelated polyndrous females and related monandrous females (Fig. 5b).

Percent egg viability was significantly influenced by the mating system of females mating system of males and females was also significant $\left(F_{2,89}=8.81 ; P=0.000\right)$ Percent egg viability was maximum when monandrous and polyandrous females mated with unrelated polygynous males and minimum when mated with related polygynous males (Fig. 6a).

When monogynous and polygynous males mated with females of varying mating system, both male $\left(F_{1,89}=6.96 ; P=0.01\right)$ and female mating systems $\left(F_{2,89}=205.30 ; P=0.000\right)$ 
more when monogynous and polygynous males mated with unrelated monandrous females and less when both males mated with related monandrous females (Fig. 6b).

\section{DISCUSSION}

The present study reveals that mating system of the mates significantly affects mate choice, mating and reproductive parameters. Monandrous and polyandrous females preferred polygynous males over monogynous one. However, when choice was given between unrelated monogynous and related polygynous males, then unrelated monogynous males were preferred. In male mate choice trials, both monogynous and polygynous males preferred monandrous females over polyandrous females. However, this preference was strongly affected by relatedness, with the choice being reversed if polyandrous females were unrelated and monogamous ones were related.

The preference for polygynous males over monogynous males can be indicative of the fitness of males in terms of more sperm supply and their viability. In T. casteneum it was reported that females respond better when they were subjected to more sexually conflicted males (Michalczyk et al., 2011). According to the 'good gene' hypothesis superior quality males were preferred for direct and indirect benefits (Simmons, 2001). Another reason for preferring the polygynous males is their ability to compete. According to Kvarnemo and Simmons (2013), females prefer to mate with males which are superior competitors and have good genetic quality so that their sons could also have the superior ability to compete.

The biasness for polygynous males was also observed in mating and reproductive parameters. Females mated faster with polygynous males and also mated for the longer duration which can be attributed to their polyandrous nature. Fecundity and percent egg viability was much higher when mated with polygynous males. Studies by Demont et al. (2014) on flour beetle reported that polygynous males are more efficient in terms of 
294 providing healthy sperms and get chance to mate more easily. Another reason which can be

295 indicative for the preference of polygynous males is novelty. It has been reported in many

296 studies that new males were preferred over old ones (Madsen et al.,1992; Olsson \& Madsen,

297 1995). Theoretical studies have revealed that mating with multiple mates or new males can

298 benefit their offspring (Yasui, 1998). In bumble bee, Bombus terrestris L., it has been

299 reported that mating with different males can reduce the chances of parasitic infection (Baer

300 and Hempel, 1999). Increased number of eggs can be attributed as one of the benefits of

polyandry. Arnqvist \& Nilsson (2000) reviewed that mating multiple times and with

polygynous males have benefits beyond providing sperms, such as more accessory proteins

which also enhance the reproductive output of females (Chen, 1984; Gillott, 1988; Eberhard

\& Cordero, 1995; Eberhard, 1996; Klowden, 1999). Females of D.melanogaster, due to their

polyandrous nature can allocate male sperms and produce more number of eggs (Childress \&

Hartle, 1972). In ladybirds, reproductive benefits of mating with polygynous males have been

reported in A. bipunctata, Propylea quatuordecimpunctata (L.), Harmonia quadripunctata

(Pontoppidan) (Majerus, 1994), M. sexmaculatus (F.) (Bind, 2007), C. septempunctata

(Omkar \& Srivastava, 2002), C. transversalis (Omkar \& James, 2005), P. dissecta (Omkar \&

Mishra, 2005) and C. saucia (Omkar et al.,2010).

In male mate choice trials, both monogynous and polygynous males preferred monandrous females. This could possibly be to avoid sperm competition in order to gain more paternity share. Short time to commence mating and longer copulation duration of these pairs can also be attributed to the mate guarding by not allowing their partners to mate with others. More fecundity and percent egg viability could be indicative of increased sperm 
al.,1963). In broad-horned beetle, G. cornutus, it was reported that males can recognise the cuticular hydrocarbons of the other males and increase their duration of mating as well as their ability to compete with sperms of other males (Lane et al.,2015). Females of many species mating with multiple partners can affect female fecundity or the potential for sperm competition (Carazo et al.,2004). Lane et al. (2015) also reported that males adjust their pre and postcopulatory investments depending on the mating status of the females. Results of various studies also reveals that males use chemical cues to assess the mating status of females (Carazo et al. 2004; Friberg 2006) and risk of sperm competition (Friberg 2006; Carazo et al., 2007; Thomas and Simmons 2009; Garbaczewska et al., 2013). In ladybird $M$. sexmaculatus, also it was reported that males adapted to various strategies such as mate guarding to avoid the risk of sperm competition (Chaudhary et al.,2015) and also preferred unmated females over multiple mated females (Dubey et al., 2018).

In second experiment when relatedness was also included, monandrous and polyandrous females preferred unrelated monogynous males. This could be attributed to inbreeding avoidance. Reduced number of eggs following matings between relatives has also been reported in D. melanogaster (Robinson et al., 2012). It has been considered as a postcopulatory strategy for inbreeding avoidance in order to lessen the cost of mating with close relatives (Tregenza \& Wedell, 2000). Decreased percent egg viability could be attributed to the biased nature of females for the sperms of related males (Charlesworth \& Charlesworth, 1987; Zeh \& Zeh, 1996, 1997; Tregenza \& Wedell, 2000) and also the poor offspring quality (Keller \&Waller, 2002). In M. sexmaculatus it was established that related individuals are less preferred over unrelated individuals (Saxena et al.,2016).

Thus, it can be concluded from the above study that (i) both monandrous and polyandrous females preferred polygynous males over monogynous in order to choose a broader gene pool for their offspring, (ii) between related polygynous and unrelated 
monogynous males, unrelated males were preferred to avoid inbreeding (iii) when monogynous and polygynous males were subjected to mate choice trials both prefer monandrous females in order to reduce the risk of sperm competition.

\section{Conflict of Interest}

It is certified that all authors have contributed significantly, and all authors are in agreement with the content of the manuscript and have no conflict of interest.

\section{Acknowledgements}

SS also acknowledges BSR Fellowship by University Grant Commission, New Delhi, India (F.No.25-1/2014-15 (BSR)/7-109/2007/BSR) dated August 25, 2015.

\section{REFERENCES}

Arnqvist, G. \& Nilsson, T. (2000). The evolution of polyandry: multiple matings and female fitness in insects. Animal Behaviour, 60, 145-164. https://doi.org/10.1006/anbe.2000.1446

Arnqvist, G. (1989). Multiple mating in a water strider: mutual benefits or intersexual conflict? Animal Behaviour, 38(5),749-756. https://doi.org/10.1016/S0003-3472(89)80107-1

Baer, B. \& Schmid-Hempel, P.(1999). Experimental variation in polyandry affects parasite loads and fitness in a bumble-bee. Nature, 397 (6715), 151. https://doi.org/10.1038/16451

Barbosa, M \& Magurran, A.E. (2010). Guppies control offspring size at birth in response to differences in population sex ratio. Biological Journal of the Linnean Society, 100(2), 414419. https://doi.org/10.1111/j.1095-8312.2010.01425.x

Bateman, A. J. (1948). Intra-sexual selection in Drosophila. Heredity, 2, 349-368.

Bezzerides, A., Iyengar, V.K. \& Eisner, T. (2008). Female promiscuity does not lead to increased fertility or fecundity in an arctiid moth (Utetheisa ornatrix). Journal of Insect Behaviour, 21, 213-221.

Bind, R.B. (2007). Reproductive behavior of generalist aphidophagous ladybird beetle, Cheilomenes sexmaculata (Coleoptera: Coccinellidae). International Journal of Tropical Insect Science, 27(2), 78 - 84. https://doi.org/10.1017/S1742758407814688

Blyth, J.E. \& Gilburn, A.S., (2006). Extreme promiscuity in a mating system dominated by sexual conflict. Journal of Insect Behavior, 19(4), 447-455. https://doi.org/10.1007/s10905006-9034-3

Burton-Chellew, M.N., Beukeboom, L.W., West, S.A. \& Shuker, D.M. (2007). Laboratory evolution of polyandry in the parasitoid wasp, Nasonia vitripennis. Animal Behaviour, 74(5), 1147-1154. https://doi.org/10.1016/j.anbehav.2006.09.028 
377 Carazo, P., Sanchez, E., Font, E.\& Desfilis, E. (2004). Chemosensory cues allow male

378 Tenebrio molitor beetles to assess the reproductive status of potential mates. Animal

379 Behaviour, 68(1), 123-129. https://doi.org/10.1016/j.anbehav.2003.10.014

380 Chapman, T., Liddle, L.F., Kalb, J.M., Wolfner, M.F. \& Partridge, L. (1995). Cost of mating 381 in Drosophila melanogaster females is mediated by male accessory gland products. Nature, 382 373(6511), 241. https://doi.org/10.1038/373241a0

383 Charlesworth, D. \& Charlesworth, B. (1987). Inbreeding depression and its evolutionary 384 consequences. Annual Review of Ecology and Systematics, 18(1), 237-268. 385 https://doi.org/10.1146/annurev.es.18.110187.001321

386 Chaudhary, D.D., Mishra, G. \& Omkar (2015). Prolonged mating in ladybird, Menochilus 387 sexmaculatus: A mate guarding mechanism? Journal of Asia-Pacific Entomology, 18, 453388 458. https://doi.org/10.1016/j.aspen.2015.05.003

389 Chen, P.S. (1984). The functional morphology and biochemistry of insect male accessory 390 glands and their secretions. Annual Reviews of Entomology, 29, 233-55. 391 https://doi.org/10.1146/annurev.en.29.010184.001313

392 Childress, D. \& Hartl, D.L. (1972). Sperm preference in Drosophila melanogaster. Genetics, 393 71(3), 417-427.

394 Davies, N.B. (1991). Mating systems. In J.R. Krebs, NB Davies (eds), Behavioural Ecology: 395 An Evolutionary Approach, Blackwell, Oxford. Pp. 263-294.

396 Demont, M., Grazer, V.M., Michalczyk, Ł., Millard, A.L., Sbilordo, S.H., Emerson, B.C., 397 Gage, M.J. \& Martin, O.Y. (2014). Experimental removal of sexual selection reveals 398 adaptations to polyandry in both sexes. Evolutionary Biology, 41(1), 62-70. 399 https://doi.org/10.1007/s11692-013-9246-3

400 Dubey, A. (2016). Sexual selection in ladybirds: existence and consequences 401 http://hdl.handle.net/10603/202582. Pp. 160.

402 Dubey, A., Saxena, S. \& Mishra, G. (2018). Mating experience influences mate choice and 403 reproductive output in an aphidophagous ladybird, Menochilus sexmaculatus. Animal Biology. https://doi.org/10.1163/15707563-17000128

Eberhard, W.G. (1996). Female control: sexual selection by cryptic female choice. Princeton: Princeton University Press. Pp. 501.

Eberhard, W.G.\& Cordero, C. (1995). Sexual selection by cryptic female choice on male seminal products-a new bridge between sexual selection and reproductive physiology. Trends in Ecology and Evolution, 10(12), 493-496. https://doi.org/10.1016/S0169-5347(00)89205-8

411 Emlen, S. T. \& Oring, L. W. (1977). Ecology, sexual selection, and evolution of mating 412 systems. Science, 197, 215-223. https://www.jstor.org/stable/1744497

413 Engqvist, L. \& Reinhold, K. (2006). Theoretical influence of female mating status and 414 remating propensity on male sperm allocation patterns. Journal of Evolutionary Biology, 19 415 (5), 1448-1458. https://doi.org/10.1111/j.1420-9101.2006.01134.x 
416 Evans, J.P. \& Kelley, J.L. (2008). Implications of multiple mating for offspring relatedness

417 and shoaling behaviour in juvenile guppies. Biological Letters, 4, 623-626.

418 https://doi.org/10.1098/rsbl.2008.0423

419 Firman, R.C. \& Simmons, L.W. (2012). Male house mice evolving with post-copulatory 420 sexual selection sire embryos with increased viability. Ecology Letters, 15, 42-46. 421 https://doi.org/10.1111/j.1461-0248.2011.01706.x

422 Foerster, K., Delhey, K., Johnsen, A., Lifjeld, J.T.\& Kempenaers, B. (2003). Females 423 increase offspring heterozygosity and fitness through extra-pair matings. Nature, 425,714. 424 https://doi.org/10.1038/nature01969

425 Fowler, K. \& Partridge, L. (1989). A cost of mating in female fruitflies. Nature, 338(6218), 426760.

427 Friberg, U. (2006). Male perception of female mating status: its effect on copulation duration, 428 sperm defence and female fitness. Animal Behaviour, 72(6), 1259-1268. 429 https://doi.org/10.1016/j.anbehav.2006.03.021

430 Garbaczewska, M., Billeter, J.C. \& Levine, J.D. (2013). Drosophila melanogaster males 431 increase the number of sperm in their ejaculate when perceiving rival males. Journal of Insect 432 Physiology, 59, 306-310. https://doi.org/10.1016/j.jinsphys.2012.08.016

433 Gems, D. \& Riddle, D.L. (1996). Longevity in Caenorhabditis elegans reduced by mating 434 but not gamete production. Nature, 379(6567), 723. https://doi.org/10.1038/379723a0

435 Gillott, C. (1988). Arthropoda-Insecta. In: Adiyodi, K.G., Adiyodi, R.G. (Eds.), Reproductive 436 Biology of Invertebrates, Vol. III. Accessory Sex Glands. Wiley, New York: 319-471.

437 Gowaty, P.A., Kim, Y.K. \& Anderson, W.W. (2012). No evidence of sexual selection in a 438 repetition of Bateman's classic study of Drosophila melanogaster. Proceedings of the 439 National Academy of Sciences, 109(29), 11740-11745. 440 https://doi.org/10.1073/pnas.1207851109

441 Gowaty, P.A., Kim, Y.K., Rawlings, J. \& Anderson, W.W. (2010). Polyandry increases 442 offspring viability and mother productivity but does not decrease mother survival in 443 Drosophila pseudoobscura. Proceedings of the National Academy of Sciences, 107(31), 444 13771-13776. https://doi.org/10.1073/pnas.1006174107

445 Gromko, M.H., Newport, M.E.A. \& Kortier, M.G. (1984). Sperm dependence of female 446 receptivity to remating in Drosophila melanogaster. Evolution, 38(6), 1273-1282. 447 https://doi.org/10.1111/j.1558-5646.1984.tb05649.x

448 Holman, L., Freckleton, R.P. \& Snook, R.R. (2008). What use is an infertile sperm? A 449 comparative study of sperm $\square$ heteromorphic Drosophila. Evolution: International Journal of 450 Organic Evolution, 62(2), 374-385. https://doi.org/10.1111/j.1558-5646.2007.00280.x

451 Keller, L.F. \& Waller, D.M. (2002). Inbreeding effects in wild populations. Trends in 452 Ecology and Evolution, 17, 230-241. https://doi.org/10.1016/S0169-5347(02)02489-8

453 Kelly, C.D. \& Jennions, M.D. (2011). Sexual selection and sperm quantity: meta $\square$ analyses of 454 strategic ejaculation. Biological Reviews, 86(4), 863-884. https://doi.org/10.1111/j.1469-

455 185X.2011.00175.X 
456 Klowden, M.J. (1999). The check is in the male: male mosquitoes affect female physiology

457 and behavior. Journal of the American Mosquito Control Association-Mosquito News, 15(2),

$458 \quad 213-220$.

459 Kvarnemo, C. \& Simmons, L.W. (2013). Polyandry as a mediator of sexual selection before 460 and after mating. Philosophical Transactions of Royal Society B, 368(1613), 20120042. 461 https://doi.org/10.1098/rstb.2012.0042

462 Lane, S.M., Solino, J.H., Mitchell, C., Blount, J.D., Okada, K., Hunt, J. \& House, C.M. 463 (2015). Rival male chemicals cues evoke changes in male pre- and post-copulatory 464 investment in a flour beetle. Behavioural Ecology, 26(4), 1021-1029. 465 https://doi.org/10.1093/beheco/arv047

466 Liu, X.P., He, H.M., Kuang, X.J. \& Xue, F.S. (2010). A comparison of female fitness 467 between monogamy and polyandry in the cabbage beetle, Colaphellus bowringi. Animal 468 Behaviour, 79(6), 1391-1395. https://doi.org/10.1016/j.anbehav.2010.03.019

469 Madsen, T., Shine, R., Loman, J. \& Hakansson, T. (1992). Why do female adders copulate so 470 frequently? Nature (London), 355, 440-441. https://doi.org/10.1038/355440a0

471 Majerus, M.E.N. (1994). Ladybirds. Harper Collins, UK.

472 Michalczyk, Ł., Millard, A.L., Martin, O.Y., Lumley, A.J., Emerson, B.C. \& Gage, M.J. 473 (2011). Experimental evolution exposes female and male responses to sexual selection and 474 conflict in Tribolium castaneum. Evolution: International Journal of Organic Evolution, 475 65(3), 713-724. https://doi.org/10.1111/j.1558-5646.2010.01174.x

476 Michaud, J.P., Bista, M., Mishra, G. \& Omkar (2013). Sexual activity diminishes male 477 virility in two Coccinella species: consequences for female fertility and progeny 478 development. Bulletin of Entomological Research, 103(5), 570-577. 479 https://doi.org/10.1017/S0007485313000199

480 Muggleton, J., Lonsdale, D. \& Benham, B.R., (1975). Melanism in Adalia bipunctata L. 481 (Col., Coccinellidae) and its relationship to atmospheric pollution. Journal of Applied 482 Ecology, 12, 451-464. 10.2307/2402167 https://www.jstor.org/stable/2402167

483 Nedvěd, O. \& Honěk, A. (2012). Life History and Development. In: Ecology and Behaviour 484 of the Ladybird Beetles (Coccinellidae) (eds. Hodek, I., van Emden, H.F., and Honěk, A.): 485 13-53. Wiley-Blackwell, Hoboken, New Jersey, USA.

486 O'DONALD, P. \& Majerus, M.E.N. (1984). Polymorphism of melanic ladybirds maintained 487 by frequency $\square$ dependent sexual selection. Biological Journal of the Linnean Society, $488 \quad 23(2 \square 3)$,

489 Olsson, M.\& Madsen, T. (1995). Female choice on male quantitative traits in lizards-why is 490 it so rare? Behavioral Ecology and Sociobiology, 36(3), 179-184. 491 https://doi.org/10.1007/BF00177794

492 Omkar \& James, B.E. (2005). Reproductive behaviour of an aphidophagous ladybeetle, 493 Coccinella transversalis Fabricius. International Journal of Tropical Insect Science, 25(2), $49496-102$. https://doi.org/10.1111/j.1439-0418.2005.00996.x 
495 Omkar \& Mishra G. (2005). Mating in aphidophagous ladybirds: costs and benefits. Journal 496 of Applied Entomology, 129(8), 432-436. https://doi.org/10.1111/j.1439-0418.2005.00996.x

497 Omkar, Singh, S.K. \& Mishra, G. (2010). Multiple matingss affect the reproductive 498 performance of the aphidophagous ladybird beetle, Coelophora saucia (Coleoptera: 499 Coccinellidae). Euroupean Journal of Entomology, 107, 177-182. 500 http://www.eje.cz/scripts/viewabstract.php?abstract=1525

501 Opp, S.B. \& Prokopy, R.J. (1986). Variation in laboratory oviposition by Rhagoletis 502 pomonella (Diptera: Tephritidae) in relation to mating status. Annals of the Entomological 503 Society of America, 79(4), 705-710. https://doi.org/10.1093/aesa/79.4.705

504 Pai, A.T. \& Bernasconi, G. (2008). Polyandry and female control: the red flour beetle 505 Tribolium castaneum as a case study. Evolution, 310(2), 148 -159. 506 https://doi.org/10.1002/jez.b.21164

507 Reynolds, J.D., (1996). Animal breeding systems. Trends in Ecology and Evolution, 11(2), 508 68-72. https://doi.org/10.1016/0169-5347(96)81045-7.

509 Ridley, M. (1988). Mating frequency and fecundity in insects. Biological Reviews, 63(4), 510 509-549. https://doi.org/10.1111/j.1469-185X.1988.tb00669.x

511 Robinson, S.P., Kennington, W.J.,\& Simmons, L.W. (2012). Preference for related mates in 512 the fruit fly, Drosophila melanogaster. Animal Behaviour, 84, 1169-1176. 513 https://doi.org/10.1016/j.anbehav.2012.08.020

514 Rolff, J., \& M.T. Siva-Jothy. (2002). Copulation corrupts immunity: A mechanism for a cost 515 of mating in insects. Proceedings of National Academy of Sciences, 99, 9916-9918.

516 Ronn, J., Katvala, M. \& Arnqvist, G. (2006). The costs of mating and egg production in 517 Callosobruchus seed beetles. Animal Behaviour, 72, 335-342.

518 Saxena, S., Mishra, G. \& Omkar (2016). Inbreeding avoidance in aphidophagous ladybird 519 beetles: a case study in Menochilus sexmaculatus. Canadian Journal of Zoology, 94(5), 361520 365. https://doi.org/10.1139/cjz-2015-0174

521 Shuker, D.M., Phillimore, A.J., Burton-Chellew, M.N., Hodge, S.E. \& West, S.A., (2007). 522 The quantitative genetic basis of polyandry in the parasitoid wasp, Nasonia vitripennis. 523 Heredity, 98(2), 69. https://doi.org/10.1038/sj.hdy.6800897

524 Shuster, S.M. \& Wade, M.J. (2003). Mating systems and strategies. Princeton University 525 Press: NJ. Pp. 533.

526 Simmons, L.W. (2001). The evolution of polyandry: an examination of the genetic 527 incompatibility and good-sperm hypotheses. Journal of Evolutionary Biology, 14, 585-594. 528 https://doi.org/10.1046/j.1420-9101.2001.00309.x

529 Simmons, L.W. (2005). The evolution of polyandry: sperm competition, sperm selection and 530 offspring viability. Annual Reviews of Ecology, Evolution and Systematics, 36, 125-146. 531 https://doi.org/10.1146/annurev.ecolsys.36.102403.112501

532 Siva $\square$ Jothy, M.T., Tsubaki, Y. \& Hooper, R.E. (1998). Decreased immune response as a 533 proximate cost of copulation and oviposition in a damselfly. Physiological Entomology, 534 23(3), 274-277. https://doi.org/10.1046/j.1365-3032.1998.233090.x 
Sloggett, J.J. \& Hone`k, A. (2012). Genetic studies. In Ecology and Behaviour of the Ladybird Beetles (Coccinellidae) (Eds. Hodek, I., Van Emden, H.F. and Honek, A.). WileyBlackwell: Chichester. Pp. 13-53.

Smith, J.M. (1956). Fertility, mating behaviour and sexual selection in Drosophila subobscura. Journal of Genetics, 54(2), 261. https://doi.org/10.1007/BF02982781

Tang-Martínez, Z. (2010). Bateman's Principles: Original experiment and modern data for and against. Encyclopedia of Animal Behavior, eds Breed MD, Moore J (Academic Press, Oxford, UK), pp166-176.

Thomas, M.L. \& Simmons, L.W. (2008). Sexual dimorphism in cuticular hydrocarbons of the Australian field cricket Teleogryllus oceanicus (Orthoptera: Gryllidae). Journal of Insect Physiology, 54(6), 1081-1089. https://doi.org/10.1016/j.jinsphys.2008.04.012

Thornhill, R. \& Alcock, J. (1983). The evolution of insect mating systems. Harvard University Press: Cambridge, Massachusetts, Pp. 576.

Tregenza, T. \&Wedell, N. (2002). Polyandrous females avoid costs of inbreeding. Nature, 415, 71-73. https://doi.org/10.1038/415071a

Trivers, R. (1972). Parental investment and sexual selection. In B. Campbell (Ed.), Sexual selection and the descent of man 1871-1971.Chicago: Aldine. Pp. 136-179).

Vahed, K. (1998). The function of nuptial feeding in insects: review of empirical studies. Biological Reviews, 73, 43-78. https://doi.org/10.1017/S0006323197005112

Vehrencamp, S.L. \& Bradbury, J.W. (1984). Mating systems and ecology. In: Behavioural ecology: an evolutionary approach, 2, (Eds. Krebs, J.R. and Davies, N.B., Sinauer: Sunderland. Pp.251-278.

Wilson, J. R., KuehnR. E., \& Beach, F. A. (1963). Modification in the sexual behavior of male rats produced by changing the stimulus female. Journal of Comparitive Physiology and Psychology, 56, 636-644. https://psycnet.apa.org/doi/10.1037/h0042469

Yasui, Y. (1998). The genetic benefits $\square$ of female multiple mating reconsidered. Trends in Ecology and Evolution, 13, 246-250. https://doi.org/10.1016/S0169-5347(98)01383-4

Yasui, Y. (1998). The genetic benefits $\square$ of female multiple mating reconsidered. Trends in Ecology and Evolution, 13, 246-250. https://doi.org/10.1016/S0169-5347(98)01383-4

Zeh, J.A. \& Zeh, D.W. (1996). The evolution of polyandry. I: intragenomic conflict and genetic incompatibility. Proceedings of Royal Society London B, 263, 1711-1717. https://doi.org/10.1098/rspb.1996.0250

Zeh, J.A. \& Zeh, D.W. (1997). The evolution of polyandry II: post-copulatory defenses against genetic incompatibility. Proceedings of the Royal Society of London B: Biological Sciences, 264(1378), 69-75. https://doi.org/10.1098/rspb.1997.0010 


\section{Figure Legends:}

574 Figure 1: Mate preference of a) monoandrous females, and b) polyandrous females.

575 Figure 2: Mate preference of a) monogynous males, and b) polygynous males.

576 Figure 3: Time of commencement of mating when a) monandrous and polyandrous females, 577 and b) monogynous and polygynous males mated with adults of different mating pattern.

578 Figure 4: Copulation duration when a)monandrous and polyandrous females, and b) 579 monogynous and polygynous males mated with adults of different mating pattern.

580 Figure 5: Fecundity when a) monandrous and polyandrous females, and b) monogynous and 581 polygynous males mated with adults of different mating pattern.

582 Figure 6: Percent egg viability when a) monandrous and polyandrous females, and b) 583 monogynous and polygynous males mated with adults of different mating pattern. 
bioRxiv preprint doi: https://doi.org/10.1101/2020.03.19.991737; this version posted March 20, 2020. The copyright holder for this (which was not certified by peer review) is the author/funder, who has granted bioRxiv a license to display the preprint in perpetuity. available under aCC-BY-NC-ND 4.0 International license.

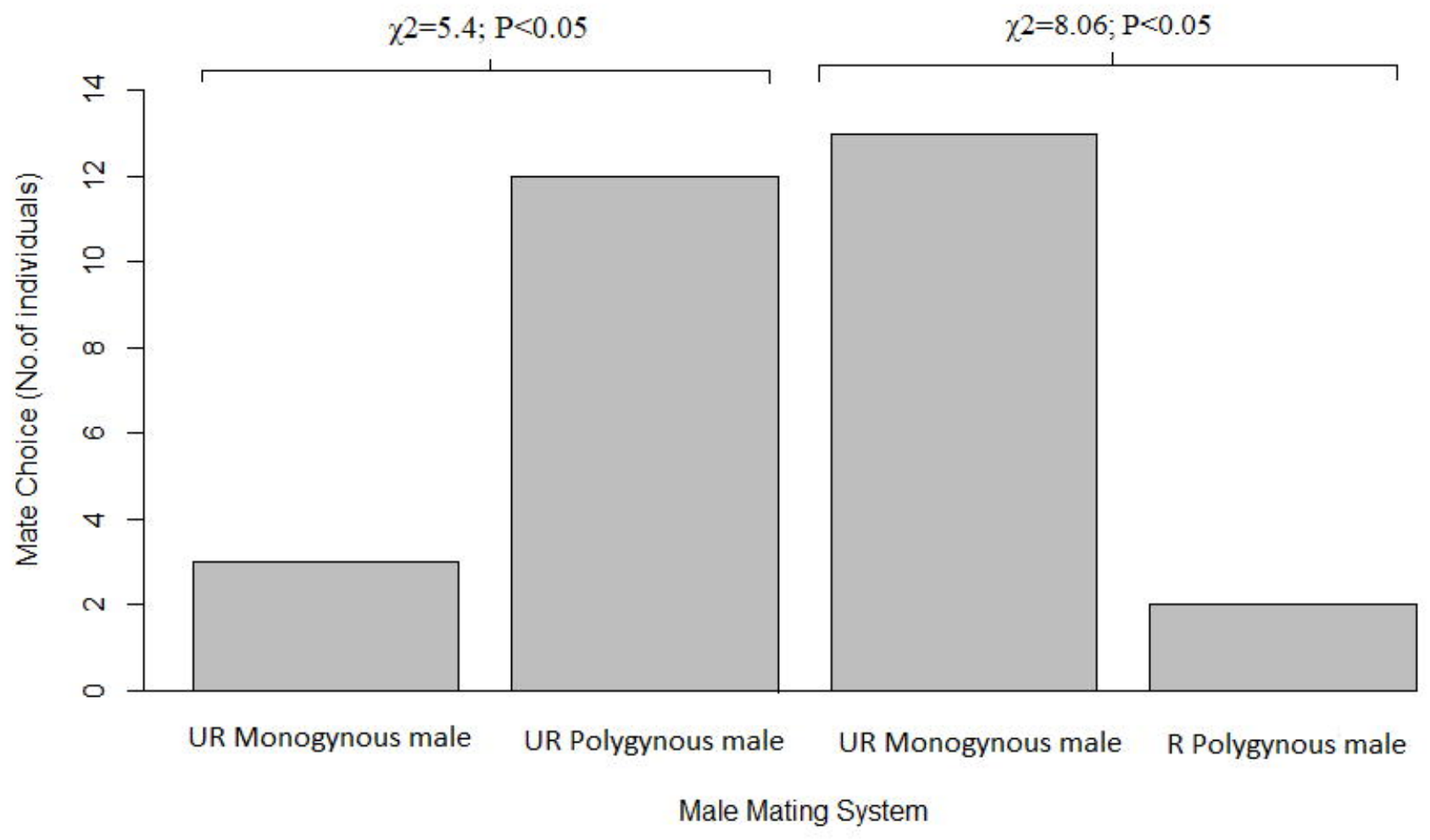

(a)

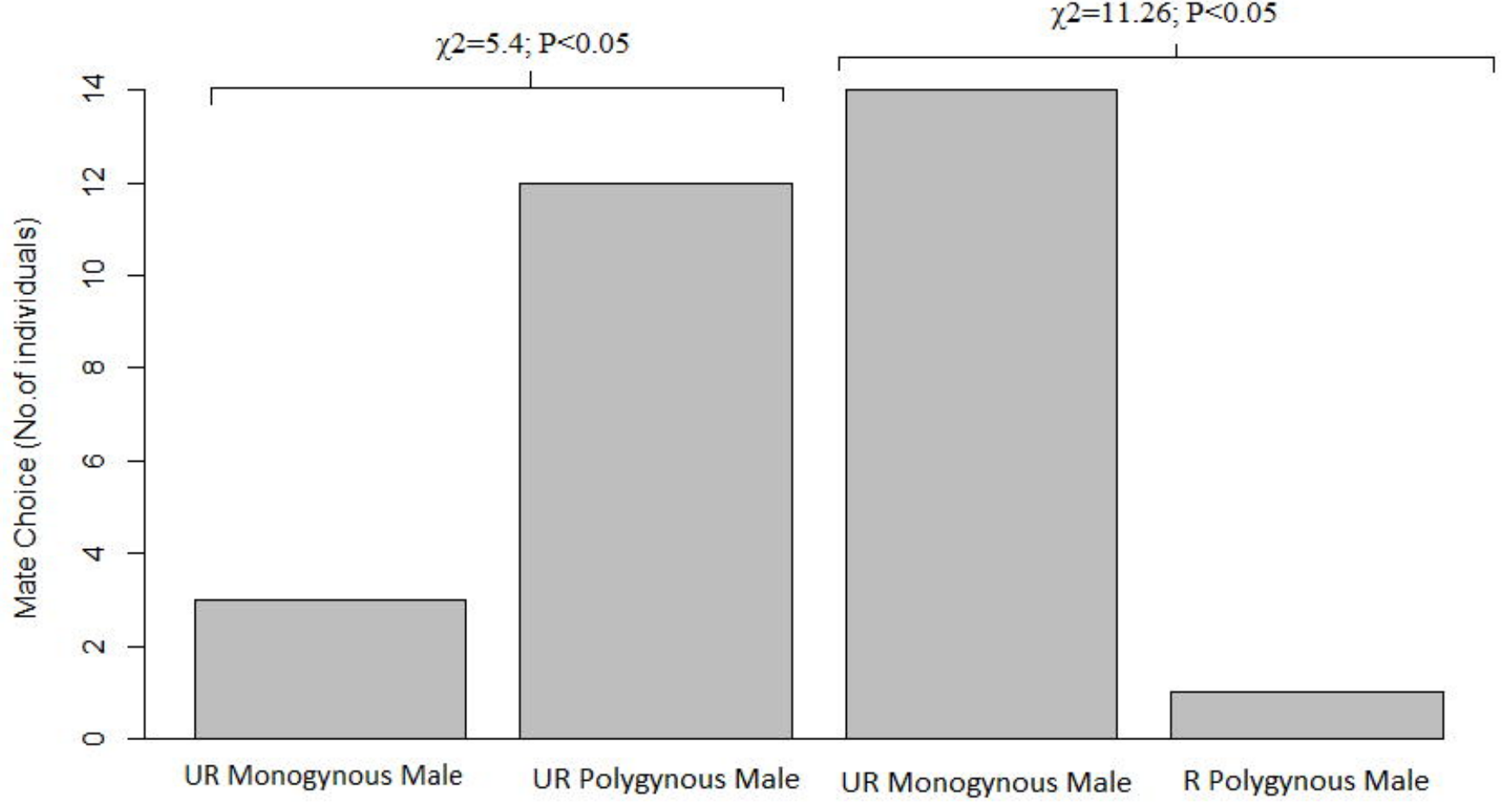

Male Mating System

(b)

Figure 1: Mate preference of a) monoandrous females, and b) polyandrous females; where $\mathrm{UR}=$ unrelated; $\mathrm{R}=$ related 
bioRxiv preprint doi: https://doi.org/10.1101/2020.032 $791993733_{;}$; this vepsion posted March 20, 2020. The copyright holder for this (which was not certified by peer review) is the author/funder, who has granted bioRxiv a license to display the preprint in perpetuity.

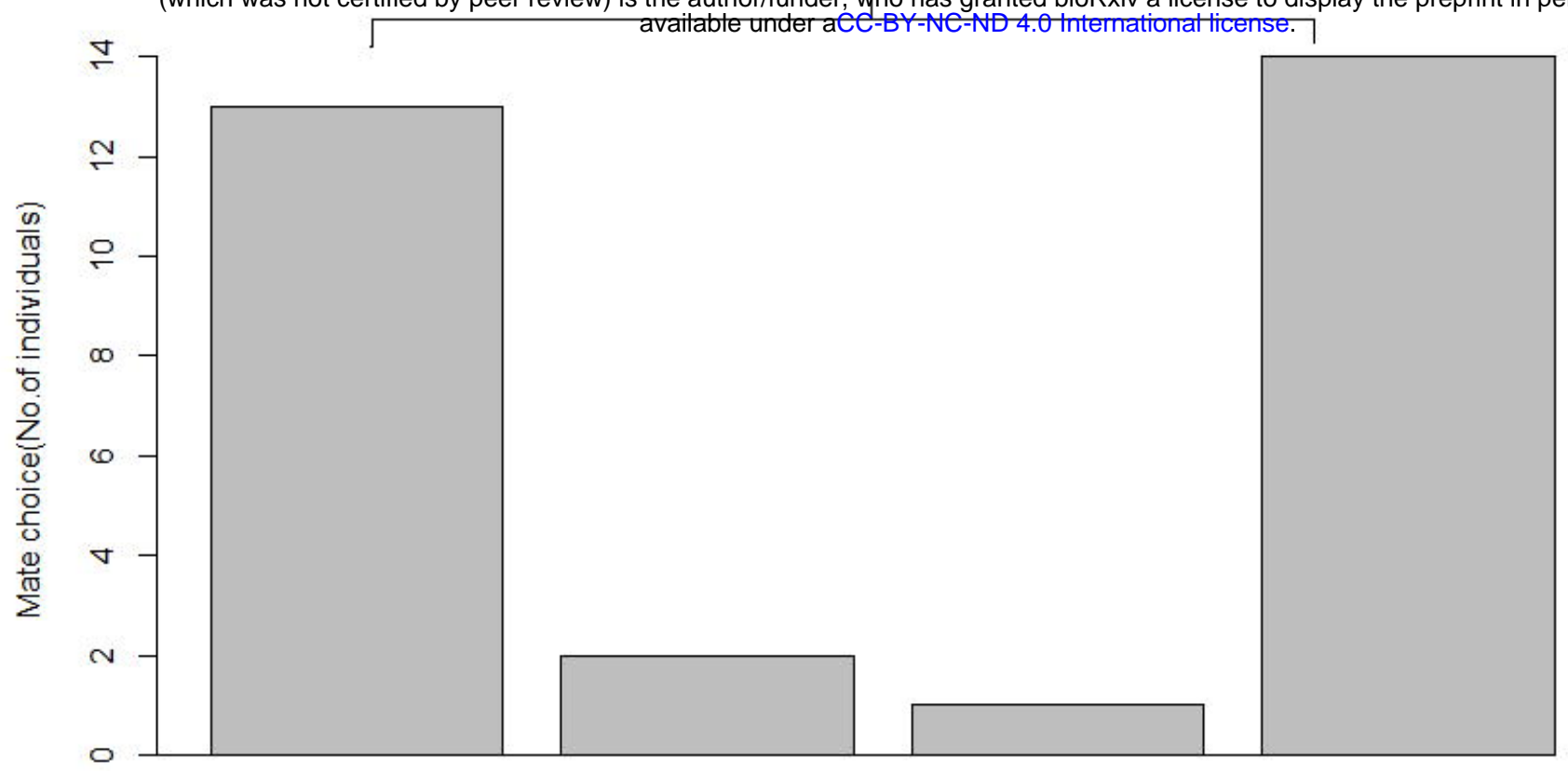

UR monandrous female UR polyandrous female R monandrous female UR polyandrous female

Female Mating System

(a)

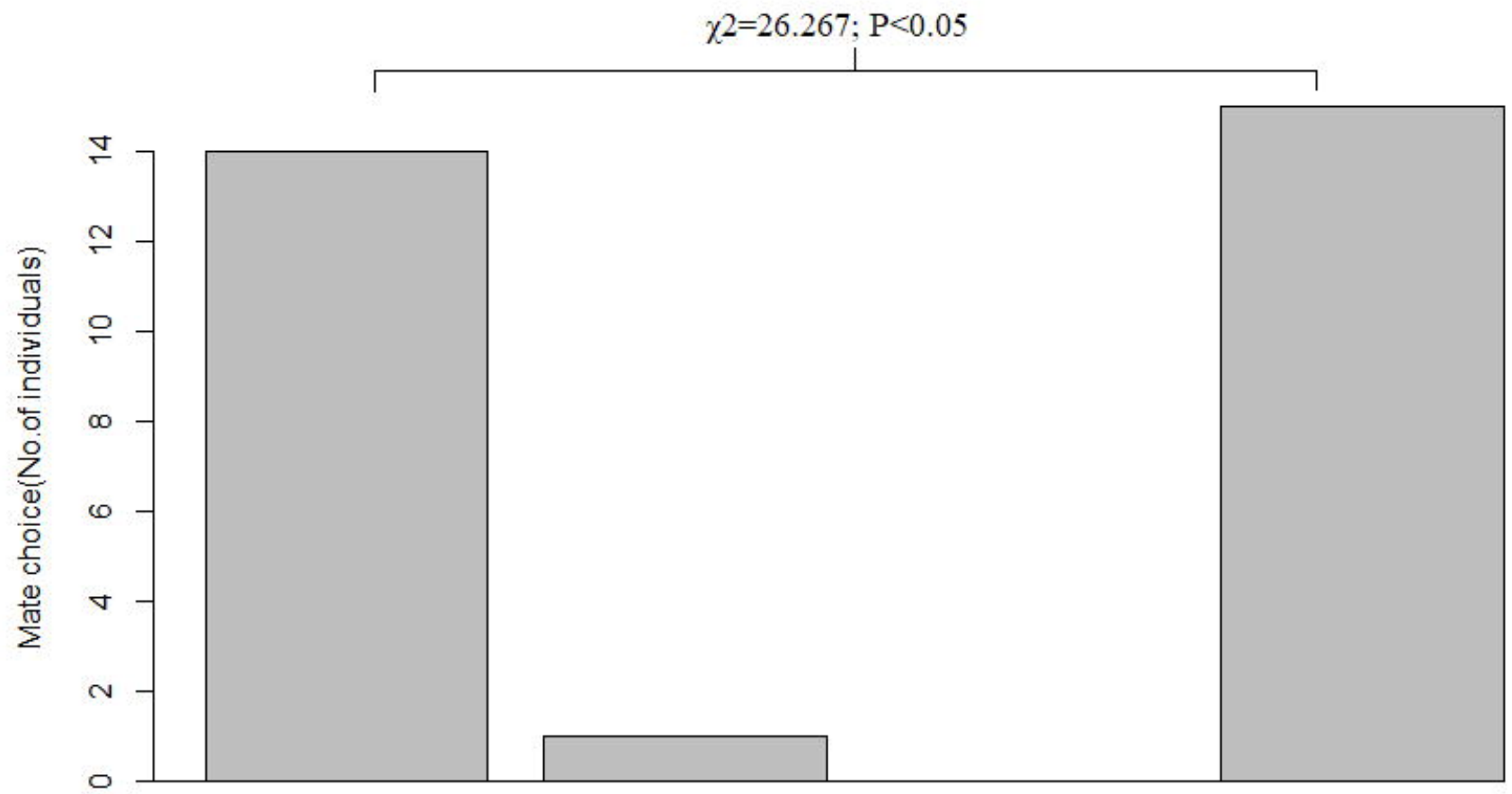

UR monandrous female UR polyandrous female R monandrous female UR polyandrous female Female Mating System

(b)

Figure 2: Mate preference of a) monogynous male, and b) polygynous male: when $U R=$ unrelated, $R=$ related 
